\title{
Are Canadian youth still exposed to second-hand smoke in homes and in cars?
}

\author{
A. Barisic, MPH (1); S. T. Leatherdale, PhD (2); R. Burkhalter, MMath (3); R. Ahmed, PhD (4)
}

This article has been peer reviewed.

\begin{abstract}
Introduction: The objective of this manuscript is to examine the prevalence of youth exposed to second-hand smoke (SHS) in homes and cars, changes in SHS exposure over time, and factors associated with beliefs youth hold regarding SHS exposure among a nationally representative sample of Canadian youth.
\end{abstract}

Methods: Descriptive analysis of SHS exposure in homes and cars was conducted using data from the Canadian Youth Smoking Survey (2004, 2006 and 2008). Logistic regression was conducted to examine factors associated with beliefs youth had about SHS exposure in 2008.

Results: In 2008, $21.5 \%$ of youth reported being exposed to SHS in their home on a daily or almost daily basis, while $27.3 \%$ reported being exposed to SHS while riding in a car at least once in the previous week. Between 2004 and 2008, the prevalence of daily SHS exposure in the home and cars decreased by $4.7 \%$ and $18.0 \%$ respectively.

Conclusion: Despite reductions in SHS exposure over time, a substantial number of Canadian youth continue to be exposed to SHS in homes and cars. Further effort is required to implement and evaluate policies designed to protect youth from SHS.

Keywords: youth, tobacco smoke pollution, prevention, car/vehicle, home/household

\section{Introduction}

Second-hand smoke (SHS) refers to the mixture of contaminants released from a burning cigarette from both the side stream smoke of the burning tobacco and the smoke that is exhaled into the air. ${ }^{1}$ The adverse health effects associated with SHS have been extensively documented; they include an increased risk of cardiovascular disease and several cancers. ${ }^{2}$ Of particular concern, however, is the emerging evidence that children are especially vulnerable to the negative health effects associated with SHS exposure. ${ }^{2}$ Children have less developed immune systems, breathe more rapidly and, as a consequence of their small size, absorb more pollutants. ${ }^{3}$ Accordingly, SHS exposure in youth has been linked to an increased risk of lower respiratory tract infections such as bronchitis and pneumonia, upper respiratory tract irritation, asthma, fluid in the middle ear, sudden infant death syndrome and decreased lung function. ${ }^{1,4-6}$ Further, SHS exposure among youth has been linked to increased days of restricted activity, bed confinement and school absence. ${ }^{7}$ There is even evidence suggesting that youth who are exposed to SHS are themselves more likely to become smokers. ${ }^{8}$

Despite evidence demonstrating the dangers of SHS exposure in vehicles, ${ }^{9}$ using
2004 YSS data, Leatherdale and Ahmed ${ }^{10}$ showed that $26.3 \%$ of Canadian youth were exposed to SHS while travelling in a vehicle at least once in the previous week. Similarly, $23.1 \%$ were exposed to SHS in their home every day, despite that the vast majority of youth reported believing that smoking should be prohibited in vehicles and in homes when children are present. ${ }^{10}$ This disparity demonstrates that youth may be unable to prevent or limit their exposure to SHS in some contexts.

The purpose of this study is to examine (1) the frequency with which youth are exposed to smoking in their homes and cars, (2) the beliefs youth hold about smoking around children in these environments, (3) changes in prevalence of SHS exposure in these environments and (4) changes in beliefs about smoking between 2004 and 2008.

\section{Methods}

This study used nationally representative data collected as part of the 2004, 2006 and 2008 waves of the Canadian Youth Smoking Survey (YSS). Detailed information on the sample design, methods and survey rates for each wave of the YSS are available in print ${ }^{11-13}$ and online (www.yss .uwaterloo.ca). In brief, the target populations for all three waves consisted of all young Canadian residents in the appropriate grades attending public and private schools in 10 Canadian provinces; residents of Yukon, Nunavut and the Northwest Territories were excluded from the target populations, as were youth living in institutions or on First Nation reserves and those

\section{Author references:}

1. Prevention \& Cancer Control, Cancer Care Ontario, Toronto, Ontario, Canada

2. School of Public Health and Health Systems, University of Waterloo, Waterloo, Ontario, Canada

3. Propel Centre for Population Health Impact, University of Waterloo and the Canadian Cancer Society, Waterloo, Ontario, Canada

4. Epidemiology and Cancer Registry, Cancer Care Manitoba, Winnipeg, Manitoba, Canada

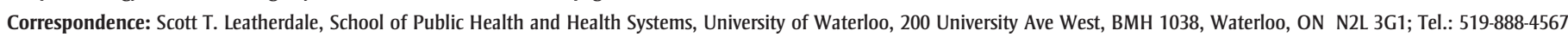
ext. 37812; Email: sleather@uwaterloo.ca 
attending special schools or schools on military bases. Data were collected using a 30- to 40-minute classroom-based survey of a representative sample of schools and students. The main design difference across the three waves of YSS is the grades sampled: the 2004 YSS sampled students in grades 5 to 9, the 2006 YSS sampled students in grades 5 to 12 and the 2008 YSS sampled students in grades 6 to 12 . In this report, we used data from respondents in grades 6 to 9 for the analyses examining changes in the prevalence of exposure to SHS in homes and in cars over time (2004, $\mathrm{n}=23362 ; 2006, \mathrm{n}=33955 ; 2008$, $\mathrm{n}=31249$ ) and data from the full sample of 2008 YSS respondents (grades 6-12; $\mathrm{n}=51922$ ) for the predictive modeling.

Each wave of the YSS collected information on SHS exposure in homes and in cars, beliefs about smoking in these environments, smoking behaviour, demographic characteristics and spending money. The measures used are consistent across YSS waves and other literature. ${ }^{10,14}$ Beliefs about smoking were assessed by asking, "Should smoking be allowed around kids at home?" (“yes" / “no” / “I don’t know”) and "Should smoking be allowed around kids in cars?" ("yes" / "no" / “I don't know”). Respondents were asked "What are the rules about smoking in your home?" ("no one is allowed to smoke in my home" / "only special guests are allowed to smoke in my home" / "people are allowed to smoke only in certain areas in my home" / "people are allowed to smoke anywhere in my home"), "Excluding yourself, how many people smoke inside your home every day or almost every day?" ("none” / "1 person" / "2 people" / "3 or more people”) and "During the past 7 days, on how many days did you ride in a car with someone who was smoking cigarettes?" ("0 days" / " 1 or 2 days" / "3 or 4 days" / “"5 or 6 days” / “all 7 days”).

\section{Analyses}

Using the 2008 data from respondents in grades 6 to 12, we examined descriptive analyses of SHS exposure, beliefs about smoking, smoking status and demographic characteristics by sex. For the descriptive statistics, we used survey weights to adjust for non-response between provinces and groups, thereby minimizing any bias in the analyses caused by differential response rates across regions or groups. Generalized linear mixed models (using PROC GLIMMIX in SAS 9.2 [SAS Institute Inc., Cary, NC, US]) were used with the unweighted data to test whether being exposed to smoking at home or in the car was associated with the beliefs youth have about smoking around youth in either the home or the car, after controlling for sociodemographic variables (sex, smoking status, parental smoking and rules about smoking in the home) and adjusting for clustering within schools.

\section{Results}

Descriptive statistics for youth in grades 6 to 9 by year of data collection (2004, 2006 and 2008) are shown in Table 1. Descriptive statistics for youth in grades 6 to 12 by sex for 2008 are shown in Table 2. Figure 1 shows changes in the prevalence of youth reporting that they live in a smoke-free home by region, while Figure 2 shows changes in the prevalence

TABLE 1

Descriptive statistics for Canadian youth in grades 6-9, by year of data collection, Canada

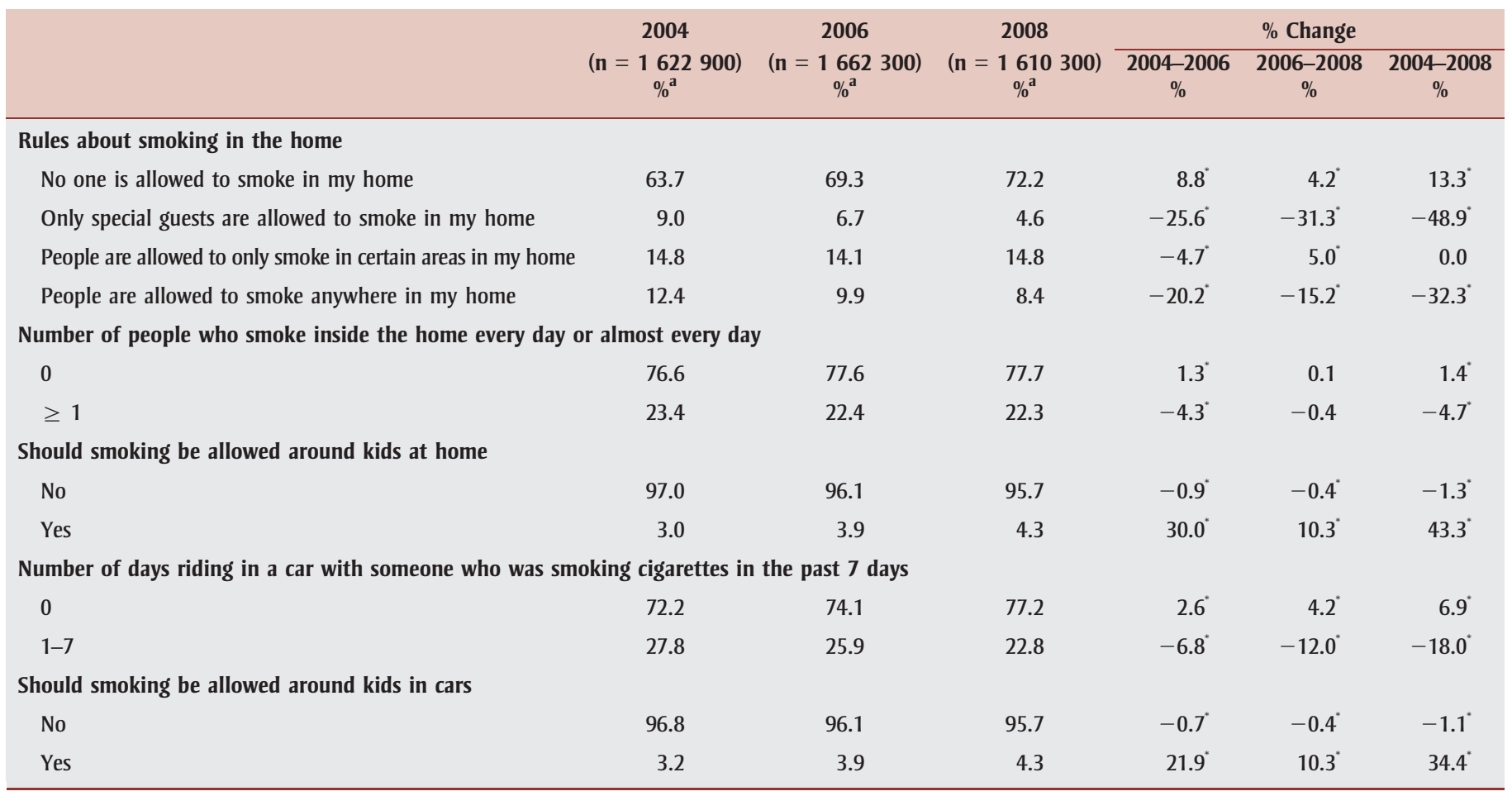

${ }^{a}$ Weighted population estimate.

${ }^{*}$ Statistically significant difference, $p<.05$. 
TABLE 2

Descriptive statistics for Canadian youth in grades 6-12, by sex, 2008, Canada

\begin{tabular}{|c|c|c|c|}
\hline & $\begin{array}{c}\text { Male } \\
(\mathrm{n}=1460300) \\
\%^{\mathrm{a}}\end{array}$ & $\begin{array}{c}\text { Female } \\
(n=1388100) \\
\%^{a^{a}}\end{array}$ & $\begin{array}{c}\text { Total } \\
(\mathrm{n}=2848500) \\
\%^{\mathrm{a}}\end{array}$ \\
\hline \multicolumn{4}{|l|}{ Grade } \\
\hline 6 & 13.1 & 13.6 & 13.3 \\
\hline 7 & 13.8 & 14.2 & 14.0 \\
\hline 8 & 14.3 & 14.5 & 14.4 \\
\hline 9 & 14.9 & 14.8 & 14.8 \\
\hline 10 & 15.5 & 14.8 & 15.2 \\
\hline 11 & 14.9 & 14.7 & 14.8 \\
\hline 12 & 13.6 & 13.4 & 13.5 \\
\hline \multicolumn{4}{|l|}{ Youth smoking status } \\
\hline Never smoker & 90.1 & 92.5 & 91.3 \\
\hline Current smoker & 8.9 & 6.4 & 7.7 \\
\hline Former smoker & 0.9 & 1.1 & 1.0 \\
\hline \multicolumn{4}{|l|}{ Parental smoking status } \\
\hline No parent(s) smoke & 56.1 & 57.0 & 56.5 \\
\hline At least 1 parent smokes & 43.9 & 43.0 & 43.5 \\
\hline \multicolumn{4}{|l|}{ Region } \\
\hline Atlantic Canada ${ }^{b}$ & 6.7 & 7.2 & 6.9 \\
\hline Quebec & 19.3 & 19.4 & 19.4 \\
\hline Ontario & 41.4 & 40.5 & 40.9 \\
\hline Prairies $^{c}$ & 18.8 & 19.1 & 18.9 \\
\hline British Columbia & 13.8 & 13.9 & 13.9 \\
\hline \multicolumn{4}{|l|}{ Rules about smoking in the home } \\
\hline No one is allowed to smoke in my home & 73.3 & 73.6 & 73.4 \\
\hline $\begin{array}{l}\text { Only special guests are allowed to smoke in my } \\
\text { home }\end{array}$ & 4.4 & 4.5 & 4.5 \\
\hline $\begin{array}{l}\text { People are allowed to only smoke in certain areas } \\
\text { in my home }\end{array}$ & 13.7 & 14.1 & 13.9 \\
\hline $\begin{array}{l}\text { People are allowed to smoke anywhere in my } \\
\text { home }\end{array}$ & 8.6 & 7.8 & 8.2 \\
\hline \multicolumn{4}{|c|}{ Number of people who smoke inside the home every day or almost every day } \\
\hline 0 & 78.3 & 78.7 & 78.5 \\
\hline$\geq 1$ & 21.7 & 21.3 & 21.5 \\
\hline \multicolumn{4}{|l|}{ Should smoking be allowed around kids at home? } \\
\hline No & 93.2 & 97.2 & 95.2 \\
\hline Yes & 6.8 & 2.8 & 4.8 \\
\hline \multicolumn{4}{|c|}{ Number of days riding in a car with someone who was smoking cigarettes in the past 7 days } \\
\hline 0 & 73.0 & 72.4 & 72.7 \\
\hline $1-7$ & 27.0 & 27.6 & 27.3 \\
\hline \multicolumn{4}{|l|}{ Should smoking be allowed around kids in cars? } \\
\hline No & 93.2 & 97.2 & 95.2 \\
\hline Yes & 6.8 & 2.8 & 4.8 \\
\hline
\end{tabular}

${ }^{a}$ Weighted population estimate.

b New Brunswick, Prince Edward Island, Nova Scotia, Newfoundland and Labrador.

c Alberta, Saskatchewan, Manitoba. of youth reporting that they were exposed to smoking while riding in car in the previous 7 days, also by region. Figure 3 shows the changes in prevalence of exposure to smoking in homes and cars over time by sex and Figure 4 shows the prevalence of exposure to smoking and the beliefs about exposure held by students in grades 6 to 12 in 2008 .

\section{Exposure to smoking in the home}

In 2008, about one-fifth $(21.5 \%$; $\mathrm{n}=605300)$ of Canadian youth in grades 6 to 12 were exposed to someone smoking in the home on a daily or almost daily basis, with rates of exposure similar in both male and female students (see Table 2). Moreover, $26.6 \%$ ( $\mathrm{n}=743200)$ of youth reported living in a home where smoking is not completely restricted, with similar rates among male and female students. However, rates did vary by province $\left(\chi^{2}=2959.6\right.$; $d f=12 ; p<.0001)$. Ontario had the highest percentage of youth living in a home where respondents reported smoking is completely restricted $(80.0 \%)$, while Quebec had the lowest percentage of smoke-free homes (56.1\%; data not shown).

Between 2004 and 2008, the prevalence of youth in grades 6 to 9 reporting that no one is allowed to smoke in the home increased by $13.3 \%$ (Table 1). In addition, the prevalence of youth reporting that people are allowed to smoke anywhere in the home decreased by $32.3 \%$. However, the prevalence of youth reporting being exposed to SHS inside the home on a daily or almost daily basis decreased by only $4.7 \%$. Further, this decrease was only observed among female youth, with the prevalence increasing among male youth. For all provinces, except British Columbia, there was an increase in the prevalence of youth who reported no exposure to SHS in the home over time (Figure 1).

\section{Exposure to smoking in cars}

In 2008 , over one-quarter $(27.3 \%$; $\mathrm{n}=716500)$ of youth in grades 6 to 12 had ridden in a car within the previous 7 days with someone who was smoking; male and female youth reporting similar rates of exposure. However, rates varied across provinces $\left(\chi^{2}=1138.1 ; d f=4\right.$; 


\section{FIGURE 1}

Changes in the prevalence of youth in grades 6 to 9 reporting that they live in a home where no one is allowed to smoke inside, by region of Canada, 2004, 2006, 2008

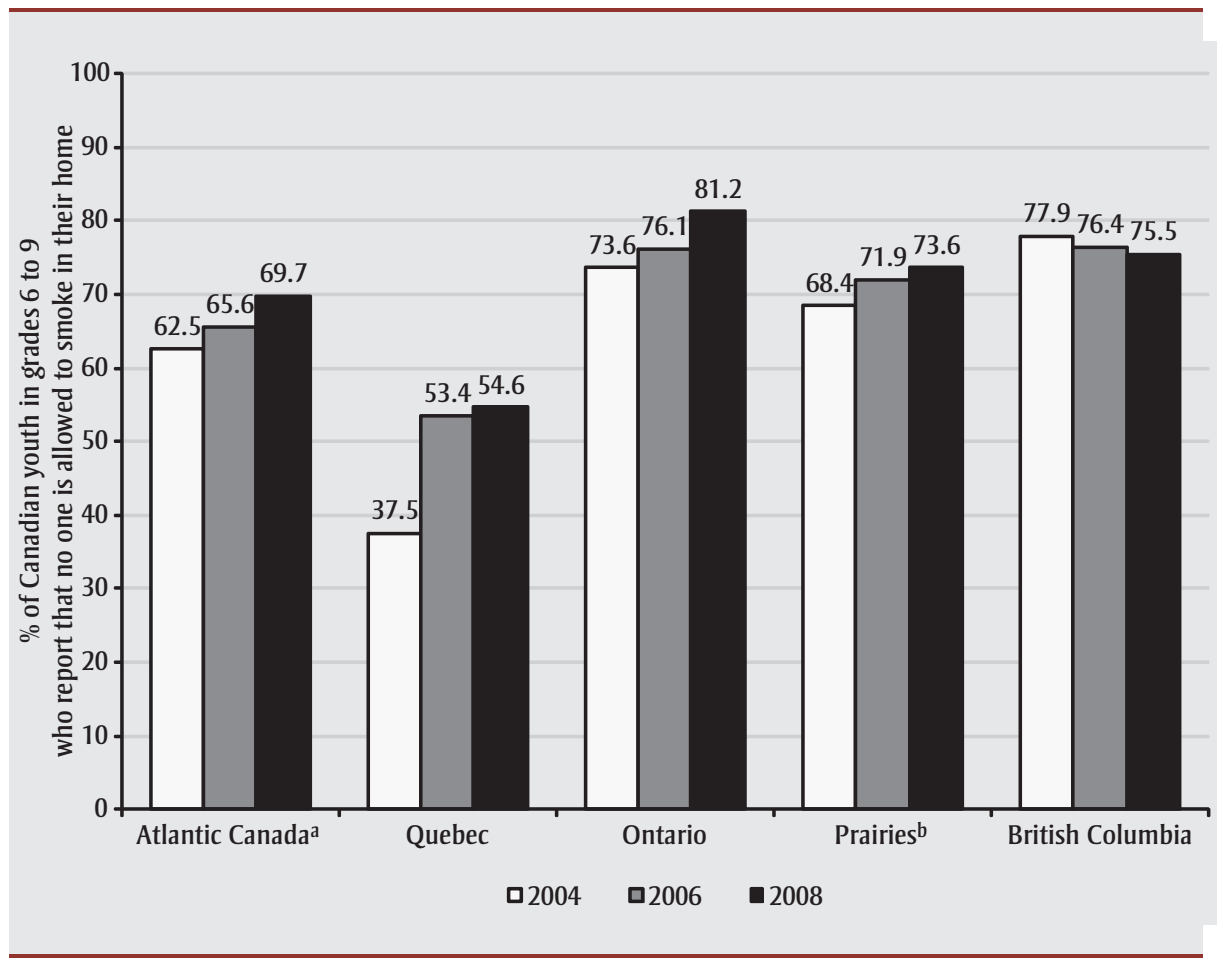

Source: 2004, 2006, 2008 Canadian Youth Smoking Surveys. ${ }^{11,12,13}$

${ }^{a}$ New Brunswick, Prince Edward Island, Nova Scotia, Newfoundland and Labrador.

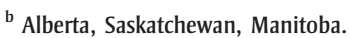

$p<.0001$ ), with the prevalence lowest in Ontario $(20.1 \%)$ and highest in Quebec (37.5\%; data not shown).

The prevalence of youth in grades 6 to 9 reporting being exposed to SHS in cars decreased by $18.0 \%$ between 2004 and 2008 (Table 1), as well as across all provinces except Quebec and British Columbia (Figure 2).

\section{Beliefs about smoking at home}

In 2008, the majority (95.2\%; $\mathrm{n}=2473$ 900) of youth in grades 6 to 12 felt that smoking should not be permitted around children at home (Table 2). This belief was more commonly held by female students (97.2\%) than by male students (93.2\%) $\left(\chi^{2}=420.4 ; d f=1 ; p<.0001\right)$. Such beliefs about smoking in the home also varied across provinces $\left(\chi^{2}=127.8\right.$; $d f=4 ; p<.0001)$, being most common among youth living in Ontario (96.3\%) and least common among those living in Quebec (93.4\%; data not shown).
For both sexes combined, the prevalence of youth in grades 6 to 9 who felt smoking should not be permitted around children at home decreased slightly by $1.3 \%$ between 2004 and 2008 .

\section{Beliefs about smoking in cars}

In 2008, the majority ( $95.2 \% ; \mathrm{n}=2484900$ ) of youth in grades 6 to 12 felt smoking should not be permitted around children in cars (Table 2). This belief was more commonly held by female students (97.2\%) than by male students (93.2\%) $\left(\chi^{2}=419.5 ; d f=1 ; p<.0001\right)$ and also varied across provinces $\left(\chi^{2}=133.5\right.$; $d f=4 ; p<.0001)$, being the strongest among youth living in Ontario (96.4\%) and the weakest among youth living in Quebec (93.5\%; data not shown).

For both sexes combined, the prevalence of youth in grades 6 to 9 who felt smoking should not be permitted around children in cars decreased by $1.1 \%$ between 2004 and 2008 .
Factors associated with beliefs about smoking in the home

In comparison to their female counterparts, male youth in grades 6 to 12 in 2008 were more likely to report that smoking should not be permitted around children in the home (odds ratio $[\mathrm{OR}]=2.43$; 95\% confidence interval [CI]: 2.20-2.69; Table 3). In comparison to current smokers, both former $(\mathrm{OR}=1.82 ; 95 \% \mathrm{CI}$ : 1.23-2.71) and never smokers (OR $=4.26$; 95\% CI: 3.78-4.79) were more likely to report smoking should not be permitted around children in the home. In comparison to youth who live in a home where smoking is completely restricted, youth who reported living in a home where smoking is allowed are also more likely to report smoking should not be permitted around children in the home $(\mathrm{OR}=1.71$; $95 \%$ CI: 1.50-1.96). Similarly, in comparison to youth who reported no SHS exposure in the car in the previous week, youth who reported riding in a car in the previous week with someone who was smoking were more likely to report that smoking should not be permitted around children in the home $(\mathrm{OR}=2.04 ; 95 \% \mathrm{CI}$ : 1.81-2.29).

\section{Factors associated with beliefs about smoking in cars}

In comparison to their female counterparts, male youth in grades 6 to 12 in 2008 were more likely to report that smoking around children should not be permitted in cars (OR $=2.58 ; 95 \% \mathrm{CI}: 2.33-2.85)$. In comparison to current smokers, both former $(\mathrm{OR}=2.02 ; 95 \% \mathrm{CI}: 1.39-2.94)$ and never smokers $(\mathrm{OR}=4.14 ; 95 \% \mathrm{CI}$ : 3.68-4.65) were more likely to report that smoking around children should not be permitted in cars. In comparison to youth who live in a home where smoking is completely restricted, youth who reported living in a home where smoking is allowed were more likely to report that smoking around children should not be permitted in cars (OR $=1.59 ; 95 \% \mathrm{CI}: 1.39-1.82)$. Similarly, in comparison to youth who reported no SHS exposure in the car in the previous week, youth who reported riding in a car in the previous week with someone who was smoking were more likely to report that smoking should not be per- 
FIGURE 2

Changes in the prevalence of youth in grades 6 to 9 reporting that they were exposed to smoking while riding in a car in the previous 7 days, by region of Canada, 2004, 2006, 2008

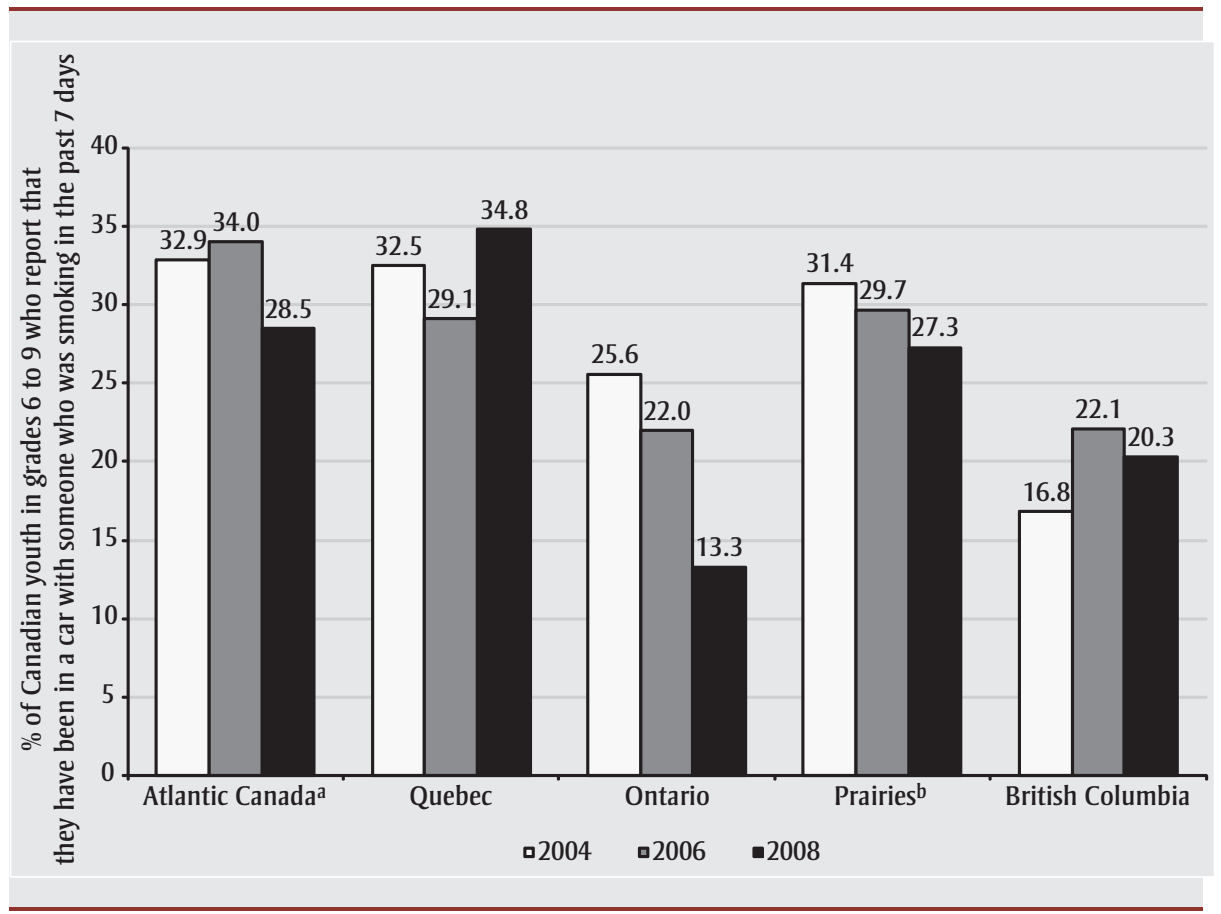

Source: 2004, 2006, 2008 Canadian Youth Smoking Surveys. ${ }^{11,12,13}$

${ }^{a}$ New Brunswick, Prince Edward Island, Nova Scotia, Newfoundland and Labrador.

${ }^{\mathrm{b}}$ Alberta, Saskatchewan, Manitoba.

mitted around children in cars $(\mathrm{OR}=2.73$; $95 \%$ CI: 2.42-3.07).

\section{Discussion}

Our study identified that, although the prevalence of youth exposed to SHS in the home and in cars decreased between 2004 and 2008, a substantial number of youth continue to be regularly exposed to SHS. The majority of youth also continue to report that smoking should not be per- mitted around children in these environments, with youth who are exposed to SHS in the home or in cars more likely to report that smoking should not be permitted around children in these contexts.

It appears that youth may not be able to prevent or limit their SHS exposure in certain contexts, suggesting that, despite the many programs aimed at protecting children from the harm associated with SHS exposure in the home and in cars, stronger and more effective programs or policies are required. For instance, in 2008 the Canadian Lung Association launched the Stop Smoking in Cars! Our Kids Deserve it! campaign, a mass media campaign designed to raise awareness and provide parents with information as well as to encourage Canadians to lobby their provincial governments to enact legislation prohibiting smoking in cars when children are present. ${ }^{15}$ New initiatives have also been designed to decrease SHS exposure in multi-unit dwellings (e.g. apartments, condos, housing coops, townhouses, etc.). A national website maintained by Smoke-Free Housing Canada provides information and advocates for increased voluntary smoke-free housing options across the country. ${ }^{16}$ As yet, no provinces have enacted legislation prohibiting smoking in multi-unit dwellings; however, landlords are legally permitted to voluntarily enact policies making their multi-unit dwellings smoke-free. Although the number of available smoke-free units is limited, anecdotal evidence suggests that demand for smoke-free units is increasing. For instance, the largest landlord in Manitoba, Globe General Agencies, implemented a smoke-free policy in 2006 for all their 60 apartment buildings, which applies to all suites, patios and balconies. ${ }^{17}$ The impact of such policies on youth SHS exposure has yet to be evaluated.

Based on our results, which indicate that youth may not be able to prevent or limit their SHS exposure in certain contexts, and there being no safe level of SHS exposure, ${ }^{2}$ evaluation of the effectiveness of programs and policies aimed at limiting youth exposure to SHS is needed. In pre-

FIGURE 3

Changes in the prevalence of exposure to smoking in homes and in cars among youth in grades 6 to 9 by sex, Canada, 2004, 2006, 2008
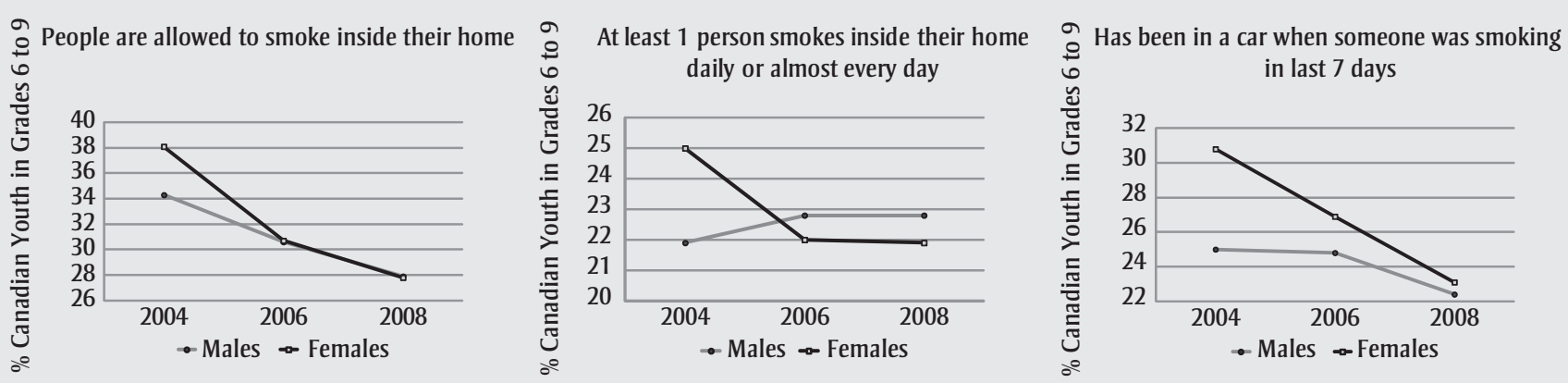

Source: 2004, 2006, 2008 Canadian Youth Smoking Surveys. ${ }^{11,12,13}$ 
FIGURE 4

Prevalence of exposure to smoking and beliefs about smoking in the home and in cars among youth in grades 6 to 12, Canada, 2008

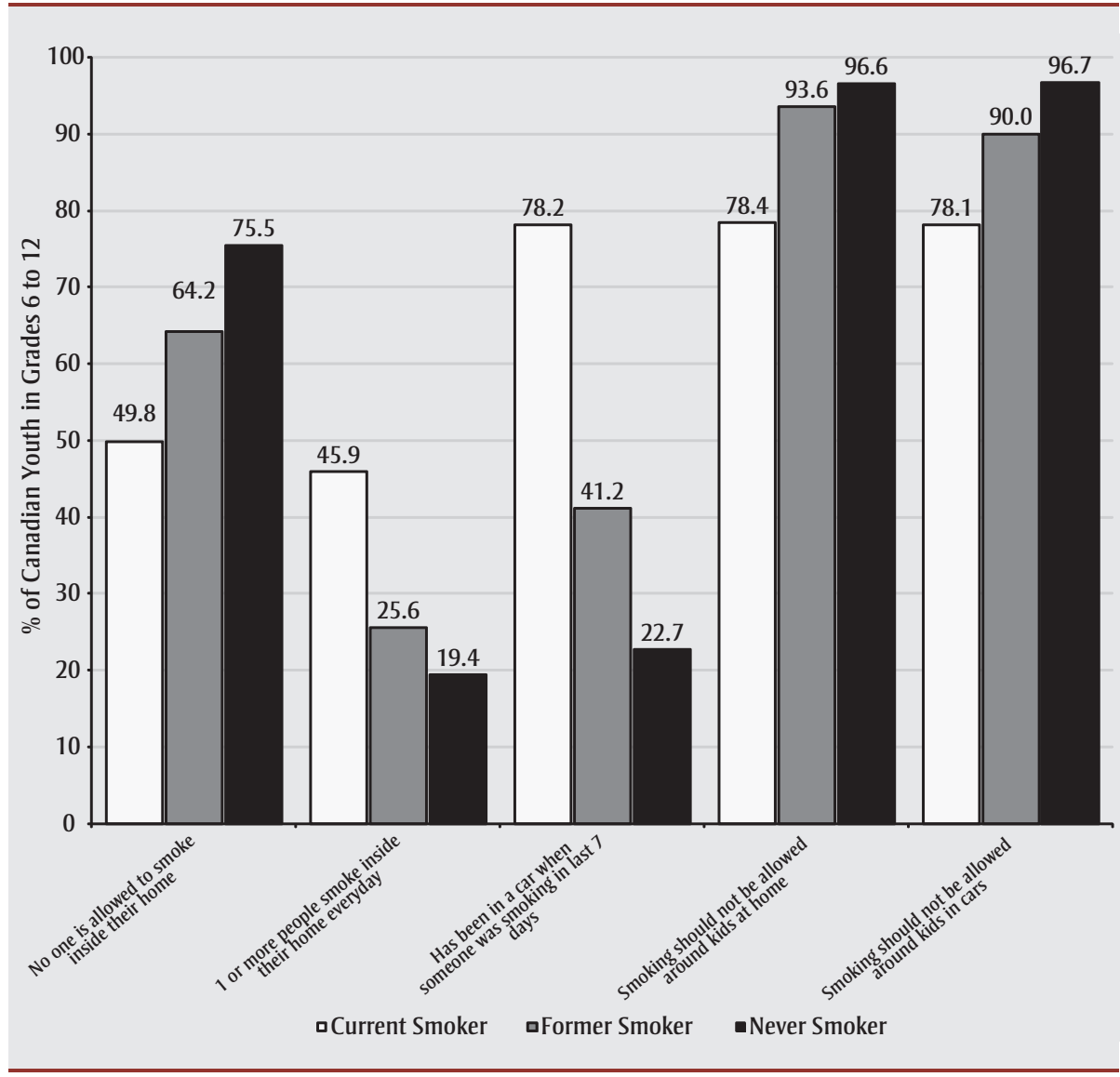

Source: 2008 Canadian Youth Smoking Survey. ${ }^{11}$

and post-campaign surveys designed to examine the effectiveness of the 20062007 Second Hand Smoke in the Home and Car Campaign, it was found that of those respondents who could recall at least one of the advertisements, $46 \%$ reported taking or planning to take action (either by not allowing smoking in their homes or cars, convincing others not to smoke or themselves quitting smoking) as a result of the advertisements. ${ }^{18}$ The surveys also found that fewer respondents had misconceptions about the ways in which to reduce SHS exposure in the home. For example, the proportion of respondents who viewed opening a window or using a fan as an effective strategy to reduce SHS exposure decreased by $17 \%$ and $10 \%$, respectively. ${ }^{18}$ However, although the results of this survey provide promising findings, more systematic research is needed to elucidate the impact of such smoke-free home policies designed to reduce SHS exposure among youth populations.
Additional research is also needed to examine the effectiveness of policies aimed at reducing SHS exposure among youth in cars. For instance, although all Canadian provinces, with the exception of Quebec, have enacted legislation prohibiting smoking in cars when children are present, ${ }^{19}$ we could identify only one Canadian study that actually examined the potential impact of these policies. Nguyen ${ }^{20}$ compared pre- and post-legislation SHS exposure using data from the Canadian Tobacco Use Monitoring Survey (CTUMS) and the YSS and found, respectively, a $10 \%$ and $26 \%$ reduction in children's exposure to SHS while riding in cars. Although the results of this study are encouraging, the evidence presented is based on cross-sectional designs so it does not really provide us with robust evidence of the effectiveness of these policies. It would be beneficial to both the research and practice community if appropriate longitudinal research designs, using natural experiments to generate real-world practice-based evidence, were used to evaluate the impact that such emerging policies have when implemented into practice. $^{21}$

The Nguyen $^{20}$ study mentioned above did not find evidence of compensatory smoking behaviour in the home as a result of smoke-free car legislation; however, previous research found evidence of increased smoking in the home after bans on smoking in public places had come into effect. $^{22}$ Taking into consideration that the home is one of the few places where smoking is still permitted, there is a need to robustly evaluate the impact of recently enacted smoke-free car legislation on compensatory SHS exposure among children. Such evaluations will have important public health impacts with regard to policies and programs aimed at decreasing SHS exposure among youth populations, and may also affect future policies and initiatives aimed at reducing SHS exposure in the home.

Our study also identified that, although the overall prevalence of youth exposed to SHS in the home and in cars has decreased over time, decreases in exposure were more prevalent among female youth than among male youth (Figure 3). In fact, male youths' exposure to SHS in the home every day or almost every day actually increased between 2004 and 2008. The reasons for this apparent sex difference are unknown; however, taking into consideration that rates of smoking are higher among male youth, parents may be more likely to expose their children to SHS if the children are themselves smokers. Or perhaps non-smokers (who are more likely to be female) are more insistent on living in a smoke-free home. The observed differences are worrisome and suggest that additional research is needed to better understand the mechanisms underlying this sex difference. Such research would provide valuable insight for developing targeted programs and policies aimed at protecting male youth.

In conclusion, this study identified that, despite that the majority of youth reported that smoking should not be permitted around children in the home or in cars, a 
TABLE 3

Logistic regression analyses examining factors associated with beliefs about smoking in the home and in cars among Canadian youth in grades 6 to 12, 2008, Canada

\begin{tabular}{|c|c|c|}
\hline \multirow[t]{2}{*}{ Parameters } & \multicolumn{2}{|c|}{$\begin{array}{l}\text { Adjusted odds ratio }{ }^{\mathrm{a}} \\
(95 \% \mathrm{Cl})\end{array}$} \\
\hline & $\begin{array}{c}\text { Model } 1 \\
\text { Smoking should not be allowed around kids } \\
\text { in the home }\end{array}$ & $\begin{array}{c}\text { Model } 2 \\
\text { Smoking should not be allowed around kids } \\
\text { in cars }\end{array}$ \\
\hline \multicolumn{3}{|l|}{ Sex } \\
\hline Female & 1.00 & 1.00 \\
\hline Current smoker & 1.00 & 1.00 \\
\hline Never smoker & $4.26(3.78-4.79)^{-*}$ & $4.14(3.68-4.65)^{*}$ \\
\hline Former smoker & $1.82(1.23-2.71)^{\circ}$ & $2.02(1.39-2.94)^{*}$ \\
\hline \multicolumn{3}{|l|}{ Parental smoking } \\
\hline \multicolumn{3}{|l|}{ Rules about smoking in the home } \\
\hline No one is allowed to smoke in the home & 1.00 & 1.00 \\
\hline Smoking is allowed inside & $1.71(1.50-1.96)^{*}$ & $1.59(1.39-1.82)^{*}$ \\
\hline \multicolumn{3}{|c|}{ Number of people who smoke inside the home every day or almost every day } \\
\hline 0 & 1.00 & 1.00 \\
\hline$\geq 1$ & $1.40(1.21-1.62)^{*}$ & $1.29(1.11-1.49)^{*}$ \\
\hline \multicolumn{3}{|c|}{ Number of days riding in a car with someone who was smoking cigarettes in the past 7 days } \\
\hline 0 & 1.00 & 1.00 \\
\hline $1-7$ & $2.04(1.81-2.29)^{*-}$ & $2.73(2.42-3.07)^{*-}$ \\
\hline
\end{tabular}

Abbreviation: $\mathrm{Cl}$, confidence interval.

Notes: Model 1: $1=$ No $(n=41317), 0=$ Yes or I don't know $(n=2043)$.

Model 2: $1=$ No $(n=41435), 0=$ Yes or I don't know $(n=2111)$.

${ }^{\text {a }}$ Odds ratios are adjusted for all other variables in the table and for region and grade.

${ }^{*} p<.01$.

** $p<.001$.

substantial number of youth continue to be regularly exposed to SHS. These findings suggest that youth may not be able to prevent or limit their own exposure, highlighting the need for research examining effective programs and policies intended to reduce exposure in youth populations.

\section{References}

1. U.S. Department of Health and Human Services. How tobacco smoke causes disease: the biology and behavioral basis for smoking-attributable disease: a report of the Surgeon General. Atlanta (GA): U.S. Department of Health and Human Services, Centers for Disease Control and Prevention, National Center for Chronic Disease Prevention and Health Promotion, Office on Smoking and Health, 2010.
2. U.S. Department of Health and Human Services. The health consequences of involuntary exposure to tobacco smoke: a report of the Surgeon General. Atlanta (GA): U.S. Department of Health and Human Services, Centers for Disease Control and Prevention, Coordinating Center for Health Promotion, National Center for Chronic Disease Prevention and Health Promotion, Office on Smoking and Health, 2006.

3. Bearer CF. Environmental health hazards: how children are different from adults. Future Child. 2005;5(2):11-26.
4. California Environmental Protection Agency. Proposed identification of environmental tobacco smoke as a toxic air contaminant. Part B: health effects. Sacramento (CA): California Environmental Protection Agency, Office of Environmental Health Hazard Assessment; 2005.

5. World Health Organization International Agency for Research on Cancer. IARC monographs on the evaluation of carcinogenic risks to humans: tobacco smoke and involuntary smoking. Volume 83. Geneva (CH): World Health Organization; 2004.

6. World Health Organization. International consultation on environmental tobacco smoke (ETS) and child health. Geneva (CH): World Health Organization; 1999. 
7. Mannino DM, Siegel M, Husten C, Rose D, Etzel R. Environmental tobacco smoke exposure and health effects in children: results from the 1991 National Health Interview Survey. Tob Control. 1996;5(1): 13-18. doi:10.1136/tc.5.1.13

8. Centers for Disease Control and Prevention. Exposure to secondhand smoke among students aged 13-15 years--worldwide, 2000-2007. MMWR. 2007;56(20):497-500.

9. Sendzik T, Fong GT, Travers MJ, Hyland A. An experimental investigation of Tobacco smoke pollution in cars. Nicotine and Tob Res. 2009;11(6):627-34.

10. Leatherdale ST, Smith P, Ahmed R. Youth exposure to smoking in homes and cars: how often does it happen and what do you think about it? Tob Control. 2008;17(2):8692 .

11. Health Canada. 2007-08 Youth Smoking Survey. Ottawa (ON): Minister of Supply and Services Canada; 2010.

12. Health Canada. 2006-07 Youth Smoking Survey. Ottawa (ON): Minister of Supply and Services Canada; 2008.

13. Health Canada. 2004-05 Youth Smoking Survey. Ottawa (ON): Minister of Supply and Services Canada; 2007.

14. Leatherdale S, Ahmed R. Second-hand smoke exposure in homes and in cars among Canadian youth: current prevalence, beliefs about exposure, and changes between 2004 and 2006. Cancer Causes Control. 2009;20(6):855-65.

15. The Lung Association. Our kids deserve it: Lung Association launches national push for smoke-free cars [Internet]. Ottawa (ON): The Lung Association; 2008 Jan 22 [cited 2011 Mar 11]. Available from: http://www .lung.ca/media-medias/news-nouvelles_e .php?id $=101$

16. Non-Smokers' Rights Association. Secondhand smoke in multi-unit dwellings [Internet]. Toronto (ON): NSRA; [cited 2011 Mar 3]. Available from: http:// www.nsra-adnf.ca/cms/page1433.cfm
17. Smoke-Free Housing Canada. What landlords, condominium owners and co-ops need to know [Internet]. [place unknown]: Smoke-Free Housing Canada; 2007 [cited 2011 Mar 3]. Available from: http://www .smokefreehousing.ca/what_owners_need _to_know.html

18. Kosir M, Gutierrez K. Lessons learned globally: secondhand smoke mass media campaigns. Saint Paul (MN): Global Dialogue for Effective Stop Smoking Campaigns, 2009.

19. Non-Smokers' Rights Association. Secondhand smoke in cars [Internet]. Toronto (ON): NSRA; [cited 2011 Mar 3]. Available from: http://www.nsra-adnf.ca/cms/page 1497.cfm

20. Nguyen HV. Do smoke-free car laws work? Evidence from a quasi-experiment. J Health Econ. 2013;32(1):138-48.

21. Leatherdale ST. Evaluating school-based tobacco control programs and policies: an opportunity gained and many opportunities lost. Can J Prog Eval. 2012;24:91-108.

22. Adda J, Cornaglia F. The effects of bans and taxes on passive smoking. Am Econ J: App Econ. 2010;2(1):1-32. 